\title{
Supervision - growing and building a sustainable general practice supervisor system
}

\author{
Jennifer S Thomson, Katrina J Anderson, Paul R Mara and Alexander D Stevenson
}

T he Australian model of vocational training for general practitioners has always been based on an apprenticeship style, where vocational trainees spend their training years in a practice attached to a designated GP supervisor. Despite substantial restructuring of the general practice vocational training system in the past decade, the apprenticeship model of training in the practice setting has remained substantially unchanged.

The model is clearly defined in the current standards of the Royal Australian College of General Practitioners (RACGP) and the Australian College of Rural and Remote Medicine. ${ }^{1,2}$ The GP supervisor is expected to undertake a central, responsible role for the vocational training of GP registrars. 3,4

Medical training in the clinical general practice setting is rapidly expanding. Government initiatives to increase general practice prevocational and vocational training positions will likely see the number of trainees in these programs double between 2007 and $2014 .{ }^{5}$ The number of medical student places has also increased, as has the requirement for clinical placements in general practice. ${ }^{6}$

If requirements and models of general practice supervision remain the same, it is possible that double the number of GP supervisors will be needed by $2014 .^{7}$ However, meeting this demand is likely to be a challenge given that:

- the general practice workforce is already stretched in its clinical load;

- a large proportion of experienced GP supervisors will reach retirement age in the next 10 years; ${ }^{8}$ and

- the workplace is an independent private business setting, where there is no requirement to participate in any increased training initiatives.

To provide appropriate clinical supervision and achieve an adequate number of skilled GP supervisors over the next few years, strategies will be needed to maintain and expand the existing supervisor workforce and capacity. Although there is limited evidence about what facilitates effective and efficient general practice supervision, this article examines a range of current and potential response options under the themes of recruitment, retention, refreshing, remodelling and resourcing. ${ }^{9}$

\section{Recruitment — filling the gaps}

\section{Motivation}

Attracting new GP supervisors will require, in part, a better understanding of the motivators for teaching. Altruism in various forms has been identified as the basis for motivation to teach, along with an interest in improving general practice quality, increasing general practice workforce, sharing values and knowledge, as well as believing teaching to be part of a GP's role. Teaching also improves morale and increases professional support and the sense of collegiality. ${ }^{10}$ Involving clinical teachers in course planning and development and curriculum design can also be an important motivator for teaching through being valued and in developing teaching roles. ${ }^{11}$

\section{ABSTRACT}

- This articles explores various models and ideas for future sustainable general practice vocational training supervision in Australia.

- The general practitioner supervisor in the clinical practice setting is currently central to training the future general practice workforce.

- Finding ways to recruit, retain and motivate both new and experienced GP teachers is discussed, as is the creation of career paths for such teachers.

- Some of the newer methods of practice-based teaching are considered for further development, including vertically integrated teaching, e-learning, wave consulting and teaching on the run, teaching teams and remote teaching.

- Approaches to supporting and resourcing teaching and the required infrastructure are also considered.

- Further research into sustaining the practice-based general practice supervision model will be required.

MJA 2011; 194: S101-S104

\section{Skilling the future general practitioners as teachers}

With universities and regional training providers (RTPs) moving towards a vertically integrated teaching model in which juniors are taught by all those senior to them, ${ }^{12}$ and both colleges now requiring the attainment of teaching skills in their curricula for all fellows, ${ }^{13,14}$ an opportunity is emerging to meet demand by providing more junior members of the profession with the skills and confidence to teach as junior registrars. This would increase the current GP teacher numbers for medical students and create a future competent, interested general practice teaching workforce. ${ }^{3}$ A survey in Western Australia showed that $77 \%$ of GP registrars were interested in a teaching role; however, only $52 \%$ of GP supervisors supported this role for GP registrars, owing to concerns about funding, time and patient load, and lack of training, GP registrar capability and space. ${ }^{15} \mathrm{~A}$ review of the literature of GP registrars as teachers confirmed these attitudes and also indicated this model needs further research and development. ${ }^{16}$ Implementation of academic registrar posts, providing registrars with foundation and advanced educational competencies, ${ }^{17}$ is another strategy to recruit future GP teachers.

\section{Semi-retired general practitioners as teachers}

Recruitment or retention of semi-retired GPs in a teaching role has been suggested. ${ }^{18}$ However, this would require a different view from the colleges, which currently expect GP supervisors to work three sessions per week in a clinical role. Noteworthy, though, is news that the Medical Board of Australia has now accepted the teaching role in its definition of medical "practice". ${ }^{19}$ 


\section{Increased teaching load}

Asking current supervisors to increase their teaching load could expand teaching capacity. Current GP supervisors have considerable interest in expanding their role to include Prevocational General Practice Placements Program (PGPPP) training; a recent survey in the Australian Capital Territory and southern New South Wales showed that $44 \%$ were prepared to do so. ${ }^{20}$

\section{Retaining and refreshing - providing professional support for GP supervisors}

Providing GP supervisors with regular access to ongoing professional development for their teaching role is important to refresh and retain the existing GP supervisor workforce. Some opportunities are listed.

\section{Access to higher education qualifications}

Access to higher education qualifications may be an incentive to some current and future supervisors. Some medical schools offer such qualifications and also fund their educators to participate. ${ }^{21}$

\section{Peer-based professional development}

The focus of professional development for teaching skills for GP supervisors has mainly been on structured teaching workshops, but other peer-based professional development models that provide more individual support and practice-based professional development, while still meeting AGPT GP supervisor curriculum requirements, could be developed further. ${ }^{4}$ It has been shown that peer support and learning activities delivered at the practice can build morale and reduce isolation. ${ }^{22}$

\section{Feedback to GP supervisors}

The provision of meaningful feedback from GP registrars to GP supervisors is important in enhancing and developing mutual skills and increasing confidence. Joint workshops, bringing GP supervisors, GP registrars and students together as both learners and teachers, can enhance the roles of all as learners along a vertically integrated continuum and provide a forum for modelling and mentoring across generations. ${ }^{23}$ For a confident GP supervisor, the learning relationship is also reciprocal, as the learners often bring with them new information and ideas that can renew the way in which a GP supervisor practises. ${ }^{4}$

\section{Remodelling}

Ensuring GP supervision models are effective and efficient will be even more important in the future; and further research and evaluation will be important in providing appropriate evidence for both new and established practices. A range of evolutionary changes to the basic model are currently being embraced.

\section{Competence-based learning}

Competence-based learning is emerging as a new approach to streamline and shorten professional learning and allow interprofessional learning and role sharing. ${ }^{24}$ This has stimulated debate in Australian medical colleges about ensuring that individual competencies are applied safely in the complex patient care context. ${ }^{25}$ Additional work is needed to identify core competencies of general practice and, specifically, those that can be safely and more efficiently taught outside the apprenticeship model.

\section{E-learning}

E-learning is a feature of the modern learning environment that increases access to educational resources for both trainee and supervisor. An increasing number of interactive learning sites and simulated learning opportunities now exist, with colleges and RTPs offering a range of e-learning tools to the GP teacher and learner. However, these web-based learning solutions must meet the needs of diverse cognitive and learning styles of GP registrars and be carefully applied and evaluated. ${ }^{26}$ As these methods increasingly form part of the clinical learning environment, it will be important to consider whether clinical teachers are able to use them to enhance teaching and reduce the supervisors' workloads.

\section{Vertical integration}

Decreasing the overall teaching load of GP supervisors as they teach at all tiers of the medical learning spectrum may be possible through the processes of vertical integration of teaching in the practice setting. ${ }^{23}$ Vertical integration has long been supported, but only recently has it become a reality in some practices that comprise all three levels of teaching - medical student, PGPPP doctor and GP registrar - and supervision.

Some teaching may be more efficiently done with a group of learners at different stages, while other learning needs must be specifically targeted. Another premise in a vertically integrated model is that some of the learning needs of the medical students and junior doctors can be addressed by the GP registrars - a process that also enhances the latter's learning. Developing and evaluating such supervision models for all levels will be an ongoing challenge.

\section{Teams of GP teachers}

The supervision model to date has tended to focus on the GP principal or senior partners as the teachers. Employee doctors within the practice are often only involved in teaching in an ad-hoc fashion, as their primary role is clinical consulting. A survey in South Australia indicated that one of the factors that enabled increasing teaching capacity in a practice was increasing the number of teachers in that practice. ${ }^{27}$ A shared model, where more GPs within the practice take on some responsibility for teaching under the coordination of a senior GP supervisor, has the potential to enhance the experience and skills for all. The model works quite well when different GP supervisors take responsibility for different levels of learners (Box). Involving others in the practice team, including practice nurses, practice managers and other health professionals, is also occurring. ${ }^{28}$

\section{The senior GP clinical supervisor}

The senior consultant role in the hospital setting, where supervision is a major focus, could be emulated in the general practice sector in the form of a senior GP clinical supervisor who would support a team of more junior supervisors/teachers in a practice. The role could be filled by senior college fellows and mentors appointed to training practices, where they would multitask as senior teachers and peer-based trainers for all levels of training medical students and junior doctors to GP registrars. ${ }^{29}$ 


\section{Remote supervision}

Remote supervision is also part of the current mix of supervision methodologies. An example of this approach is the Remote Vocational Training Scheme, which has been operating for 10 years and currently has 55 participating GP registrars: "Distance supervision is provided by phone, email, practice visits and clinical teaching visits. The supervisor is carefully selected, orientated to their new role and offered support and guidance throughout." ${ }^{130}$ Expansion of this model may be part of the solution by enabling additional training opportunities in remote locations.

\section{Time-efficient models}

With the increasing workload of general practice, time-efficient teaching models, such as "wave consulting" and "teaching on the run", are evolving and being used. "Wave consulting" allows the GP supervisor to see several booked patients while, in parallel, the junior doctor or medical student is booked to see one chosen patient slowly and independently in an adjoining room, with the GP supervisor joining and completing the consultation with the learner in a booked time frame. ${ }^{31}$ "Teaching on the run" involves quick exchanges between GP supervisor and learner, and its practical value is now recognised. ${ }^{32}$ Enabling access opportunities for such exchange, including informal exchange in tea rooms and corridor meetings, can maximise the time available for learning exchange.

\section{Resourcing}

Efficient, effective general practice vocational training requires capacity built into the total practice system with resourcing of supervisor and supervision time and infrastructure. Few studies have been undertaken of the real costs of supervision and training in general practice. Studies so far suggest that there is a net financial cost to training practices for teaching medical students, and a small net benefit for teaching junior doctors and GP registrars. ${ }^{33}$

\section{Infrastructure}

One of the significant barriers to expanding and sustaining clinical practice-based teaching is lack of physical teaching infrastructure. A number of national grant programs have provided infrastructure development support for general practice including the National Rural and Remote Health Infrastructure Program, ${ }^{34}$ the GP super clinics program ${ }^{35}$ and the Primary Care Infrastructure grants. ${ }^{35}$ The ACT government has recently provided \$2 million in general practice infrastructure development funding, with one of the objectives of this funding being to provide infrastructure for training the future ACT general practice workforce. ${ }^{36}$

The current grant model for infrastructure funding, while expanding both clinical consulting and teaching space in a small number of practices in Australia, may struggle to meet the required capital development needs for all the anticipated extra trainees. As an offsetting factor, there may be more spare teaching rooms available than previously thought - a recent survey indicated $55 \%$ of GP supervisors had access to a spare teaching room. ${ }^{20}$

Rather than a one-off grant investment approach, an alternative system of investment could be explored that would encourage GPs to invest in their practices and receive a sufficient return from teaching to allow them to initiate capital investment into their practices and ensure a sufficient return on that capital investment. This would require a change of thinking away from capital-based grant funding to improve leverage and provide for ongoing funding for facilities, leasing and teaching arrangements. It would also require differential

\section{Case study: a culture of shared teaching}

The setting is an urban general practice with four full-time and five part-time general practitioners. The two practice principals take overall responsibility, but designate key staff for the different learners. One key supervisor is allocated to the registrar, and another supervisor is allocated to the medical student. A roster is organised for the Prevocational General Practice Placements Program intern and involves five supervisors sharing the load on different days, coordinated by the principal supervisor.

Individual teaching is carried out by the designated supervisor. Group case discussions bring all the learners together with a different supervisor each week. In this way the teaching load is spread across eight doctors within the practice. New doctors to the practice are invited to join in teaching and become part of the roster. In-practice discussion around teaching happens regularly at practice team meetings. The practice manager is involved in coordinating the teaching and supervision rosters. Attendance at GP supervisor workshops or university workshops is also shared among the supervising doctors.

funding for practices engaged in teaching to build workforce capacity that allows for patient needs to be met within a teaching, as opposed to a pure service, medical practice environment.

\section{Remuneration}

Although altruism has motivated much of the teaching in general practice to date, this is not necessarily a sound basis for continued GP supervisor expansion and development. ${ }^{37}$ Current funding difficulties include:

- no publicly funded staff specialist equivalents in general practice;

- lack of recognition of the teaching role in the Medicare fee-forservice consultation system;

- teaching allowances and Practice Incentives Program payments generally not equivalent to earning while consulting; and

- current programs not usually remunerating GP registrar or junior doctors for a teaching role.

All these barriers require addressing. As an example, a recent initiative by the ACT government offered teaching incentive payments to individual GP supervisors rather than practice payments, with the objective of attracting new GP supervisors to teach Australian National University (ANU) medical students. ${ }^{38}$

\section{Streamlining administrative requirements}

There is a range of accreditation, quality assurance, reporting and payment processes which are part of general practice supervision and add to the administrative cost of clinical teaching. Initiatives by governments, universities, RTPs and colleges to streamline these processes, without compromising quality or safety, could potentially contribute materially to a sustainable system. Vertical integration at an organisational level could improve this situation.

\section{Conclusion}

The demand for clinical GP supervisors is increasing as more medical students, hospital doctors and GP registrars are being taught in the general practice clinical setting. Building a sustainable system to manage this change will require renewed efforts from all stakeholders and governments to GP supervisor workforce recruitment and retention, new models of supervision and further teaching-focused investment into general practice. 
There is a range of emerging models in general practice supervision and supervisor recruitment strategies; however, we need further research into and evaluation of the effectiveness of some of these solutions, including vertical integration models, GP teacher role development, and financial arrangements.

\section{Acknowledgements}

We acknowledge Dr Paul Goldsbrough for his assistance with the manuscript.

\section{Competing interests}

Jennifer Thomson, Katrina Anderson and Paul Mara are currently GP supervisors. Jennifer Thomson is an RACGP representative for General Practice Education and Training accreditation review teams and has worked as a consultant for research being undertaken with a grant to the ANU from Coast City Country General Practice Training.

\section{Author details}

Jennifer S Thomson, MB BS, FRACGP, MBA, Associate Professor, ${ }^{1}$ and General Practice Supervisor ${ }^{2}$

Katrina J Anderson, BMed, MTh, FRACGP, Senior Lecturer, ${ }^{1}$ and Director of Medical Education ${ }^{3}$

Paul R Mara, MB BS, FRACGP, FACRRM, Rural Practitioner and Supervisor ${ }^{4}$

Alexander D Stevenson, MB BS, DCH, FRACGP, Visiting Fellow (formerly, Academic Registrar) $^{1}$

1 School of General Practice, Rural and Indigenous Health, ANU

Medical School, Australian National University, Canberra, ACT.

2 Winnunga Nimmityjah Aboriginal Health Service, Canberra, ACT.

3 Australian Capital Territory and South East New South Wales Local

Training Group, Coast City Country General Practice Training,

Canberra, ACT.

4 Gundagai Medical Centre, Gundagai, NSW.

Correspondence:

jennifer.thomson@anu.edu.au;jenny@maxwellconsulting.com.au

\section{References}

1 Royal Australian College of General Practitioners. Standards for general practice education and training trainers and training posts 2005. Melbourne: RACGP 2005. http://www.racgp.org.au/Content/NavigationMenu/educationandtraining/vocationaltraining/RACGPGeneralPracticeVocationalTrainingStandards/ 2005_Standards_Trainers_and_Training_Posts.pdf (accessed May 2010).

2 Australian College of Rural and Remote Medicine. Standards for supervisors and teaching posts in primary rural and remote training. Brisbane: ACRRM, 2010.

3 Dodd J, Vickery A, van Osch H, Emery J. General practice registrar teaching roles - is there a need for shared understanding? Aust Fam Physician 2009; 38: 77-80.

4 Ingham G. Curriculum Framework for General Practice Supervisors. Canberra: Australian General Practice Training, 2007. http://www.agpt.com.au/Supervisors/ SupervisorResources/ (accessed May 2010).

5 Australian Government Department of Health and Ageing. Building a National Health and Hospital Network — training record number of GPs [media release 2010; 15 Mar]. Canberra: DoHA, 2010. http://www.health.gov.au/internet/ministers/publishing.nsf/Content/mr-yr10-nr-nr046.htm?OpenDocument\&yr= 2010\&mth=03 (accessed Feb 2011).

6 Crotty B. More students and less patients: the squeeze on medical teaching resources [editorial]. Med J Aust 2005; 183: 444-445.

7 Australian Government Department of Health and Ageing. Medical Training Review Panel. Eleventh report. Canberra: DoHA, Dec 2007.

8 Australian Government Department of Health and Ageing. General practice statistics. GP workforce statistics 1984-85 to 2009-10. Canberra: DoHA, 2010. http://www.health.gov.au/internet/main/publishing.nsf/Content/General+Practice+Statistics-1 (accessed May 2011).

9 Pearce R, Laurence C, Black LE, Stocks N. The challenge of teaching in a general practice setting. Med J Aust 2007; 187: 129-132.

10 Larsen K, Perkins D. Training doctors in general practices: a review of the literature. Aust J Rural Health 2006; 14: 173-177.
11 Dahlstrom J, Doeai-Raj A, McGill D, et al. What motivates senior clinicians to teach medical students? BMC Med Educ 2005; 5: 27.

12 Dick ML, King D, Mitchell G, et al. Vertical integration in Teaching And Learning (VITAL): an approach to medical education in general practice. Med J Aust 2007. 187: $133-135$

13 Royal Australian College of General Practitioners. The RACGP curriculum for Australian general practice. GPs as teachers and mentors. Melbourne: RACGP, 2007.

14 Australian College of Rural and Remote Medicine. Primary curriculum. 3rd ed. Brisbane: ACRRM, 2009.

15 Dodd J, Vickery A, van Osch H, Emery J. General practice registrar teaching roles. Aust Fam Physician 2009; 38: 77-80.

16 Rushforth B, Kirby J, Pearson D. General practice registrars as teachers: a review of the literature. Educ Prim Care 2010; 21: 221-229.

17 General Practice Education and Training. Australian General Practice Training policies (2008). Appendix 3. Guidelines for academic posts. Canberra: GPET, 2008.

18 Doctors in training. Aust Med 2011; Jan: 13.

19 Medical Board of Australia [communiqué]. 2010; 15-23 Dec. http://www.medicalboard.gov.au/News/Communique-from-the-Board.aspx (accessed Jan 2011).

20 Thomson J, Jackson AB, Anderson K, Kljakovic M. GP interest in teaching junior doctors - does practice location, size and infrastructure matter? Aust Fam Physician 2009; 38: 1000-1002.

21 Australian General Practice Training. Resources for GP supervisors. Canberra: AGPT, 2009. http://www.agpt.com.au/Supervisors/SupervisorResources (accessed Feb 2011).

22 Beyer MF, Gerlach M, Flies U, et al. The development of quality circles/peer review groups as a method of quality improvement in Europe: results of a survey in 26 European countries. Fam Pract 2003; 22: 443-451.

23 Anderson K, Thomson J. Vertical integration - reducing the load on GP teachers. Aust Fam Physician 2009; 38: 907-910

24 Frank J, Danoff D. The CanMEDS initiative: implementing an outcomes-based framework of physician competencies. Med Teach 2007; 29: 642-647.

25 Gleeson C. Education beyond competencies: a participative approach to professional development. Med Educ 2010; 44: 404-411.

26 Cook D. Learning and cognitive styles in web-based learning: theory, evidence, and application. Acad Med 2005; 80: 266-278.

27 Laurence CO, Black LE. Teaching capacity in general practice: results from a survey of practices and supervisors in South Australia. Med J Aust 2009; 191: 102 104.

28 Birks J, Farrell E, Newson A. Flexible teaching and learning in general practice. Aust Fam Physician 2004; 33: 687-689.

29 Australian College of Rural and Remote Medicine, General Practice Education and Training, General Practice Registrars Australia, Royal Australian College of General Practitioners. The future general practice education and training system. Discussion paper. Melbourne: General Practice Registrars Australia, 2009.

30 Remote Vocational Training Scheme. Registrar handbook 2010. Albury, NSW RVTS, 2010: 11.

31 DeWitt DE. Incorporating medical students into your practice. Aust Fam Physician 2006: 35: 24-26

32 Catchpole M, Albert E, Lake F, Brown T. Teaching on the run - general practice training between consultations. Aust Fam Physician 2005; 34 Suppl 1: S47-S50.

33 Laurence, CO, Black LE, Karnon J, Briggs NE. To teach or not to teach? A costbenefit analysis of teaching in private general practice. Med J Aust 2010; 193. 608-613.

34 Australian Government Department of Health and Ageing. National Rural and Remote Health Infrastructure Program. Canberra: DoHA, 2008. http:// www.health.gov.au/internet/main/publishing.nsf/Content/nrrhip-lp (accessed Feb 2011).

35 Australian Government Department of Health and Ageing. GP super clinics. Canberra: DoHA, 2008. http://www.health.gov.au/internet/main/publishing.nsf/ Content/pacd-gpsuperclinics (accessed Feb 2011).

36 Stanhope J. Supporting general practice: 2010 GP development fund round 2 opens [media release]. Canberra: Australian Capital Territory Government, 2010; 7 May. http://www.chiefminister.act.gov.au/media.php?v=9506\&m=52 (accessed Feb 2011).

37 Thistlethwaite JE. Altruism can no longer support community-based training [letter]. Med J Aust 2006; 185: 53-54

38 Stanhope J. Teaching incentive payments: supporting GPs [media release] Canberra: Australian Capital Territory Government, 2010; 19 May. http:// www.chiefminister.act.gov.au/media.php?v=9546 (accessed Feb 2011)

(Received 4 Mar 2011, accepted 14 Apr 2011) 